\section{Une barrière de diffusion permet la jouvence de la levure}

Fabrice Caudron
Institut de Biochimie, Département de Biologie, ETH Zürich, Schafmattstrasse 18, 8093 Zurich, Suisse. fabrice.caudron@bc.biol.ethz.ch
> La plupart des organismes vieillissent, c'est-à-dire que la probabilité pour un organisme de mourir augmente exponentiellement avec son âge. Afin qu'une espèce puisse subsister, les organismes nouvellement créés doivent naître sans hériter de l'âge de leurs parents pour jouir d'une longévité potentielle complète. Des organismes unicellulaires comme les bactéries ou les levures montrent aussi des signes de sénescence $[1,2]$. Chaque cellule ne peut se diviser qu'un nombre limité de fois, puis meurt. Toutefois, le compteur de l'âge est remis à zéro chez les cellules filles dont la durée de vie est similaire à celle de leurs mères [3]. Les mécanismes sous-jacents à cette jouvence commencent à être établis chez Saccharomyces cerevisiae.

\section{Accumulation de facteurs \\ de sénescence}

Au cours de ses divisions, la cellule mère de levure accumule des facteurs de sénescence. Une catégorie importante de ces facteurs est représentée par les cercles d'ADN ribosomique extra-chromosomiques (ERC, [4]), formés par excision d'ADN ribosomique chromosomique. Ils contiennent une origine de réplication et ségrégent asymétriquement pendant la mitose pour s'accumuler dans la cellule mère $[4,5]$. Le mécanisme assurant cette asymétrie est longtemps resté une énigme.

\section{La membrane nucléaire}

\section{externe est compartimentée}

La levure réalise une mitose fermée, c'està-dire que la membrane nucléaire reste intègre pendant la mitose. Le noyau de la levure en anaphase est positionné au niveau du cou, avec une partie dans la cel- lule mère (qui émet le bourgeon) et l'autre dans le bourgeon (qui deviendra la cellule fille) (Figure l) ${ }^{1}$. Des expériences de perte de fluorescence par photoblanchiment (FLIP, fluorescence loss induced by photobleaching) ont permis d'établir qu'une GFP (green fluorescent protein) nucléoplasmique et que les protéines insérées dans la membrane nucléaire interne diffusent librement de la mère vers la fille [6]. Toutefois, les protéines insérées dans la membrane nucléaire externe ou qui traversent toute l'enveloppe nucléaire, comme les pores nucléaires, ne diffusent pas librement au travers du cou, alors qu'elles diffusent dans leur compartiment membranaire. La membrane nucléaire externe de la cellule mère et celle de la cellule fille sont donc séparées par une barrière de diffusion [6]. Le résultat de cette compartimentation est que les pores nucléaires préexistants, ne pouvant pas diffuser vers la cellule fille, restent dans la cellule mère. D'autre part, des pores nucléaires sont insérés de novo dans la membrane nucléaire de la cellule fille. Ainsi, les cellules mères gardent un noyau avec de vieilles protéines dans leur membrane nucléaire, et les cellules filles construisent leur noyau avec de nouvelles protéines.

\footnotetext{
${ }^{1}$ « Au début du cycle de division cellulaire, la levure est plus ou moins ovoïde. Au site de croissance prédéterminé (selon la ploïdie), la levure va croître et ainsi commencer à former un petit bourgeon qui sera la cellule fille. Cette croissance polarisée se poursuit au cours du cycle et le bourgeon atteint une taille presque équivalente à celle de la cellule mère. Toutefois, la cellule fille n'atteint jamais la taille de la cellule mère. En laboratoire et dans les conditions optimales le temps d'un cycle de la levure est d'environ 120 min. Toutefois, la cellule fille étant plus petite que la cellule mère, il faut qu'elle compense cela et son cycle est un peu plus long (140 min) que celui de la cellule mère (100 min). Les deux cellules se séparent finalement par contraction au niveau du cou (jonction étroite entre la cellule mère et la cellule fille)» (thèse Fabrice Caudron).
}

De façon remarquable, cette rétention des pores nucléaires dans la mère permet aussi la ségrégation asymétrique des $\varepsilon R C$. En effet, les plasmides non-centromériques sont associés à la périphérie nucléaire, ancrés de façon stable aux pores nucléaires [6]. Ainsi, les ERC s'attachent aux vieux pores nucléaires et sont retenus dans la cellule mère. La cellule fille insère alors de nouveaux pores nucléaires auxquels ne sont pas associés d'ERC.

\section{Une barrière de diffusion dépendant des septines}

La diffusion des protéines de la membrane plasmique et du réticulum endoplasmique est aussi restreinte par des barrières de diffusion au niveau du cou [7-9]. La formation de ces barrières requiert les septines, qui sont des GTPases capables de s'assembler en hétéro-oligomères et de former des structures plus complexes comme des anneaux de filaments, comme c'est le cas au niveau du cortex du cou.

La barrière de diffusion observée dans la membrane nucléaire externe dépend aussi des septines [6]. L'abrogation de la barrière entraîne la diffusion des vieux pores de la cellule mère vers la cellule fille; cela permet une ségrégation beaucoup plus symétrique des ERC. Les cellules mères donnent alors une partie de leurs facteurs de sénescence à leurs filles ce qui résulte en un allongement de leur durée de vie. En revanche, les cellules filles qui héritent d'une partie de «l'âge » de leur mère vivent moins longtemps.

L'ancrage des ERC à l'enveloppe nucléaire et l'existence d'une barrière de diffusion dans la membrane nucléaire externe assurent ainsi la jouvence des cellules filles dans la levure. 


\section{Conservation des barrières}

\section{de diffusion septine dépendantes}

La compartimentation des membranes par des barrières de diffusion permet d'établir la différenciation de la cellule mère en une cellule qui vieillit, et d'effacer cet âge dans la cellule fille. Ces résultats suscitent de nombreuses questions. Tout d'abord, nous savons qu'il existe, en plus de la barrière nucléaire, des barrières de diffusion dans la membrane plasmique et dans le réticulum endoplasmique. Estce que la compartimentation de toutes ces membranes est également importante pour la jouvence de la cellule fille? Ces barrières dépendent des septines, mais quelle est leur composition moléculaire? Les barrières de diffusion ne sont pas spécifiques aux levures. Une barrière du segment initial est nécessaire pour que l'axone se différencie du compartiment somato-dendritique [10]. De plus, les septines semblent former des barrières de diffusion à la base des épines dendritiques, et dans la queue des spermatozoïdes. Ces barrières de diffusion sont nécessaires à la différenciation et la maturation des compartiments qu'elles délimitent.

Mais le plus intéressant, c'est que le rôle d'une barrière dans la jouvence n'est probablement pas restreint à la levure : l'exclusion des pores nucléaires est aussi observé pendant la spermatogenèse et dépend aussi de la présence d'un anneau qui peigne le noyau. Est-ce pour cela que nous ne naissons pas avec l'âge de nos pères? $\diamond$

\section{A diffusion barrier}

allows budding yeast rejuvenation

\section{RÉFÉRENCES}

1. Ackermann M, Stearns SC, Jenal U. Senescence in a bacterium with asymmetric division. Science 2003; $300: 19-20$.

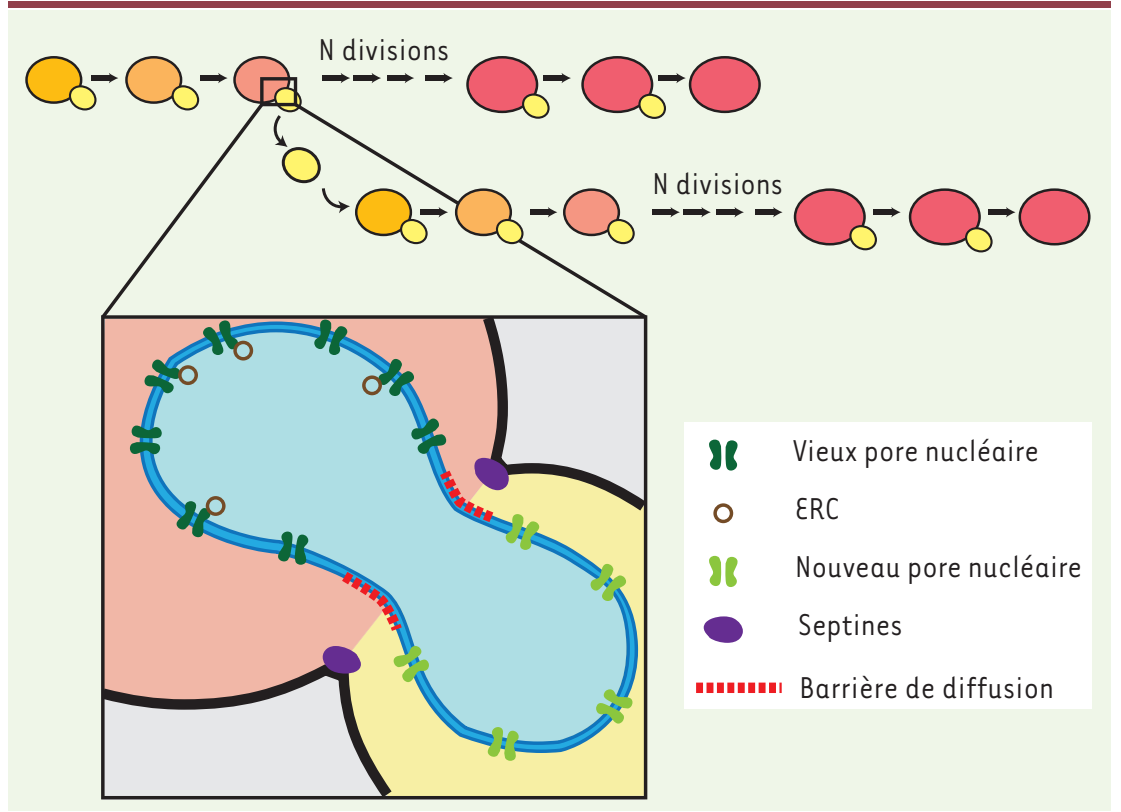

2. Mortimer RK, Johnston JR. Life span of individual yeast cells. Nature 1959 ; 183 : 1751-2.

3. Kennedy BK, Austriaco NR Jr, Guarente L. Daughter cells of Saccharomyces cerevisiae from old mothers display a reduced life span. J Cell Biol 1994 ; 127 : 1985-93.

4. Sinclair DA, Guarente L. Extrachromosomal rDNA circles: a cause of aging in yeast. Cell 1997 . $91: 1033-42$

5. Murray AW, Szostak JW. Pedigree analysis of plasmid segregation in yeast. Cell 1983; 34 : 961-70.

6. Shcheprova Z, Baldi S, Frei SB, et al. A mechanism for asymmetric segregation of age during yeast budding. Nature 2008; 454 : 728-34.

7. Barral Y, Mermall V, Mooseker MS, Snyder M. Compartmentalization of the cell cortex by septins is required for maintenance of cell polarity in yeast. Mol Cell $2000 ; 5: 841-51$.

8. Luedeke C, Frei SB, Sbalzarini I, et al. Septindependent compartmentalization of the endoplasmic reticulum during yeast polarized growth. J Cell Biol $2005 ; 169: 897-908$.

9. Takizawa PA, DeRisi JL, Wilhelm JE, Vale RD. Plasma membrane compartmentalization in yeast by messenger RNA transport and a septin diffusion barrier. Science $2000 ; 290$ : 341-4.

10. Hedstrom KL, Ogawa Y, Rasband MN. AnkyrinG is required for maintenance of the axon initial segment and neuronal polarity. J Cell Biol 2008; 183 : 635-40.

Figure 1. Jouvence de la levure : asymétrie de facteurs de sénescence (ERC) par une barrière de diffusion dans la membrane nucléaire externe. Chaque cellule de levure ne peut se diviser qu'un nombre restreint de fois. Toutefois, les cellules filles (jaune) ont le même potentiel de durée de vie que leur mère. Cadre : Schéma d'une levure en anaphase (noyau en bleu). Les septines (violet) dirigent la formation d'une barrière de diffusion (ligne en pointillés rouge) dans la membrane nucléaire externe. Les vieux pores nucléaires (vert foncé), et les ERC (cercles marrons) restent dans la cellule mère, alors que de nouveaux pores nucléaires (vert clair) sont insérés dans l'enveloppe nucléaire dirigée vers le bourgeon.

Grâce à $m / s$, vous vivez en direct

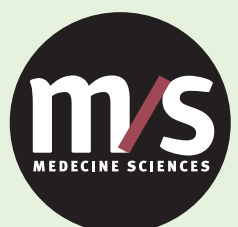

Tarifs d'abonnement M/S - 2009 les progrès des sciences biologiques et médicales

Abonnez-vous

à Médecine/Sciences

Bulletin d'abonnement page 212 dans ce numéro de $\mathrm{m} / \mathrm{s}$

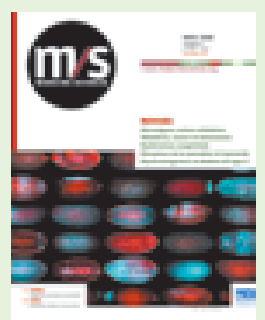

